\title{
Needleless electrospun PVA/Chitosan nano fiber membrane and its antibacterial property
}

\begin{abstract}
Poly vinyl alcohol (PVA), which is a low-volatility, environmentally friendly and water-soluble polymer, is suitable for needleless electro spinning. Chitosan (CS) has drawn much attention due to its excellent antibacterial properties; however, it is hard to needle lessly electro spin CS alone. Thus, a certain amount of CS was added into the electro spinning solution to fabricate PVA nano fibers with antibacterial properties. In this paper, a needleless electro spinning device with spiral disk spinnerets was used to prepare PVA with different concentrations of CS nano fiber membranes. The effects of electro spinning parameters on process stability and anti-water-soluble processing were investigated. The results showed that the electro spinning process was associated with voltage, rotation speed and collection distance. The optimal electro spinning parameters are a voltage of $75 \mathrm{kV}$, a rotation speed of $11 \mathrm{rpm}$ and a distance of $190 \mathrm{~mm}$. From the comparison and analysis, $5 \%$ glutaraldehyde (GA) solution treatment is the superior method to increase the anti-water-solubility of the membrane. The antibacterial properties of PVA/CS nano fiber membranes with CS concentrations ranging from $1.0 \%$ to $1.5 \%$ were also investigated. The results showed that the inhibition rates of Escherichia coli (E. coli) were all above 99\%, and those of Staphylococcus aureus (S. aureus) were all above $90 \%$. Moreover, GA solution treatment has no effect on the antibacterial performance.
\end{abstract}

Keywords: needleless electro spinning, poly vinyl alcohol, water resistance, antibacterial properties, electrospun nano fiber, biocompatibility, water solubility, chemical stability, film-forming ability, surface tension, voltage, three-level orthogonal experiment, vapor treatment, hemiacetal reaction, oscillation method, antibacterial performance
Volume I Issue 2 - 2017

Shuo Li,' Zhijuan Pan²

'College of textile \& Clothing Engineering, Soochow University, China

${ }^{2}$ College of textile \& Clothing Engineering, Soochow University, China

Correspondence: Zhijuan Pan, College of textile \& Clothing Engineering, Soochow University, No. 199 Renai Road, Suzhou, China, Tel +86 13625273222, Email zhjpan@suda.edu.cn

Received: January 12, 2017 | Published: March 22, 2017
Abbreviations: PVA, poly vinyl alcohol; GA, glutaraldehyde; CS, chitosan

\section{Introduction}

Currently, PM2.5 as a sensitive indicator has drawn public attention. Studies on new materials to filter dust, pollen and toxic materials and to effectively inhibit the growth of bacteria are needed. Electrospun nano fiber membranes, characterized by their great flexibility, ${ }^{1,2}$ light weight, high surface-to-volume ratios and porous structures, have been shown to have wide applications in many fields, especially in filtration..$^{3-6}$ However, conventional single-needle electro spinning does not satisfy industrial production due to its low productivity, and electric field interference exists for multi-needless electro spinning. ${ }^{7}$ Needleless electro spinning could solve the above problems and make industrialization possible. The main techniques for needleless electro spinning currently are tip electro spinning of the liquid surface,,$^{8-14}$ conical wire coil spinnerets, ${ }^{15}$ multi-hole/porous spinnerets ${ }^{16-18}$ and rotary cylinder/cone/disk spinnerets. ${ }^{19,20}$ Designed a perforated pipe needleless electrostatic spinning apparatus. ${ }^{21}$ The spinning jet density was relatively high, approximately 250 times that of traditional single needle electro spinning production, but the uniformity of the fibers was poor. Designed a bubble electro spinning device inspired by the spider spinning process. ${ }^{22}$ The diameter was approximately $50 \mathrm{~nm}$ at a lower voltage, but the diameter was volatile due to its susceptibility to the effect of bubble size. Designed a rotating spiral wire electrostatic spinning apparatus which greatly improved production. ${ }^{23}$ With the increase in voltage and the decrease in distance, the output of the nano fibers also increased, but little change in the diameter was observed.
Since needleless spinnerets require a significant amount of electro spinning solution exposed to air, which may change the mass percentage of the electro spinning solution because of volatilization, PVA, which exhibits low-volatility, water solubility, biocompatibility, chemical stability and film-forming ability, is suitable for needleless spinnerets. CS has advantages due to its antibacterial property, adsorption property, biocompatibility, non-toxicity, and ability to easily modify fabrication. ${ }^{24}$ However, it is difficult to electro spin pure $\mathrm{CS}$; thus, it is a better choice to fabricate PVA and CS composite nano fiber membranes. ${ }^{25}$ Blended CS and PLA solutions of different ratios and electrospun nano fiber membranes to examine inhibition rates and water filtration. The results showed that $75 \% \mathrm{CS}$ in the membrane inhibited bacterium from growth and led to better filtration than CS ratios of $25 \%$ and $50 \%$. A high concentration of honey was added into CS and PVA blended solutions by Wessam A. ${ }^{26}$ They found that honey reduced the viscosity and achieved the spinning requirement. This study demonstrates the stable manufacture of PVA/CS nano fiber membranes with good antibacterial properties using a novel needleless electro spinning method.

\section{Materials and methods}

\section{Materials}

1788PVA was obtained from Changzhou Fengyuan Textile Company. CS (M-PK-1601002 viscosity: $128 \mathrm{mPa} . \mathrm{s})$ was purchased from Zhejiang Golden-Shell Pharmaceutical Co., Ltd. E. coli (FSCC 149002 A0246B) and S. aureus were obtained from Guangdong Food Microbiological Safety Engineering Research and Development 
Center. Acetic acid was purchased from Sinopharm Chemical Reagent Co., Ltd. GA ( $50 \% \mathrm{wt} \%$ solution in $\left.\mathrm{H}_{2} \mathrm{O}\right)$ was obtained from $\mathrm{J} \& \mathrm{~K}$ Scientific, Ltd., and acetone (AR) was obtained from Shanghai Hushi Laboratorial Equipment Co., Ltd.

\section{Electro spinning of PVA/CS nano fibers}

Solutions composed of different weight ratios of PVA and CS were prepared as follows: PVA and CS (5\%:1.0\%, 5\%:1.1\%, 5\%:1.2\%, $5 \%: 1.3 \%, 5 \%: 1.4 \%$ and 5\%:1.5\%). Solutions were prepared in $1 \%$ acetic acid.

Figure 1 shows the needleless electro spinning setup (Kunshan Tungray Precision Testing Co., Ltd), which contains a stainless steel spiral disk spinneret connected to a high-voltage power, a grounded metal conveyor belt collector and a Teflon solution vessel. ${ }^{27}$ During electro spinning, the vessel was filled with the prepared PVA/CS solution with the verge of the spiral disk immersed in it. While the solution was charged with a high electrical voltage through a metal strip inside the solution vessel, PVA/CS jets were generated from the disk and collected on the rotating collector wrapped by a nonwoven substrate with $110 \mathrm{~cm}$ in length and $30 \mathrm{~cm}$ in width.

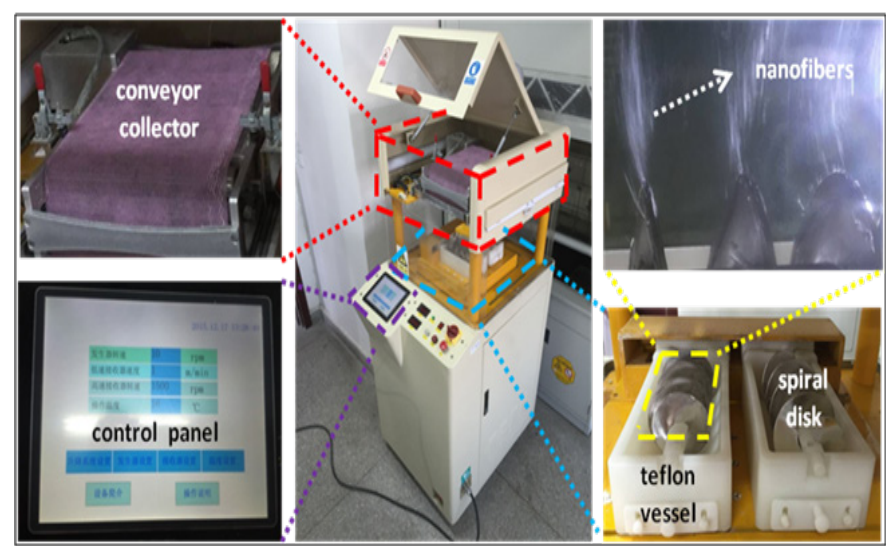

Figure IThe needleless electro spinning setup with spiral disk spinnerets.

\section{Characterization}

The conductivity and viscosity of the PVA/CS solutions were measured via a DDS-11C conductivity meter (Shanghai Precision Scientific Instrument Co., Ltd., China) and an Ar2000 rheometer (TA Instruments.US), respectively. Surface tension was measured by DCAT21 (Data physics, Germany).

The morphologies of nano fiber membranes were examined through field emission scanning electron microscope (FE-SEM, Hitachi S-4800, and Japan) images. The diameters of nano fibers were determined using an image analyzer (Image-Pro Plus 5.0) by averaging 100 measurements in SEM images.

The antimicrobial test consulted China Standard, GB/T 20944.32008 Evaluation of antibacterial property of textiles-Part 3: Oscillation method. Each experiment utilized a blank vial and standard cotton as control samples, while $0.75 \mathrm{~g}$ of PVA/CS nano fiber membranes with different concentrations of CS was set as the samples. After adding a certain concentration of E. coli and S. aureus, respectively, the samples and control samples were sterilized and placed inside an Erlenmeyer flask at $24^{\circ} \mathrm{C}$ for $1 \mathrm{~h}$ under oscillation with an oscillation speed of $150 \mathrm{r} / \mathrm{min}$. Living bacteria concentrations were calculated before and after the oscillation, and then, the inhibition rate was calculated according to Equation $1: 28$

$$
Y=\frac{\left(W_{t}-Q_{t}\right)}{W_{t}} X 100
$$

Where,

\section{Y: Inhibition rate}

$\mathrm{W}_{\mathrm{t}}$ : Mean living bacteria of blank vial after the shock

$\mathrm{Q}_{\mathrm{t}}$ : Mean living bacteria of samples after the shock

\section{Results and discussion}

\section{Solution properties}

Table 1 shows the conductivity and surface tension of PVA/ CS blended solutions. The surface tension and conductivity of the solutions increased with the addition of CS, which was in favor of the electro spinning ability. However, CS led to difficulties in the electro spinning process because of its high viscosity Figure 2. The maximum concentration of CS was $1.5 \%$ in combination with $5 \%$ PVA.

Table I Conductivity and surface tension of PVA/CS blended solutions

\begin{tabular}{lll}
\hline Solutions & Conductivity $(\mathrm{ms})$ & Surface Tension $\mathbf{~ N N / m}$ \\
\hline $1.0 \% C S+5 \% P V A$ & 1.293 & $40.837 \pm 0.029$ \\
$1.1 \% C S+5 \%$ PVA & 1.311 & $40.898 \pm 0.030$ \\
$1.2 \% C S+5 \%$ PVA & 1.404 & $41.264 \pm 0.028$ \\
$1.3 \% C S+5 \%$ PVA & 1.372 & $41.604 \pm 0.030$ \\
$1.4 \% C S+5 \%$ PVA & 1.403 & $42.049 \pm 0.030$ \\
$1.5 \% C S+5 \%$ PVA & 1.576 & $41.049 \pm 0.030$ \\
\hline
\end{tabular}

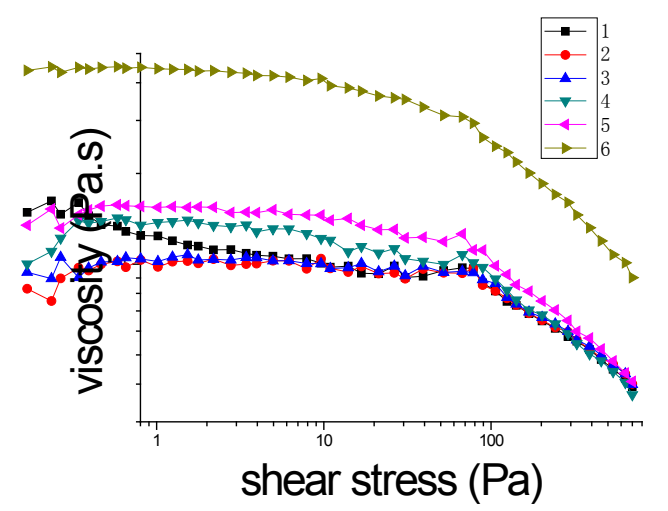

Figure 2 Variation of viscosity with shear rate increase: (I) 5\% PVA and $1.0 \%$ CS, (2) 5\% PVA and I.I\% CS, (3) 5\% PVA and I.2\% CS, (4) 5\% PVA and $1.3 \%$ CS, (5) 5\% PVA and I.4\% CS, (6) 5\% PVA and I.5\% CS.

\section{Optimization of the electro spinning parameters}

Nano fiber membranes of 5\% PVA blended with $1.3 \%$ CS was fabricated in order to examine the optimal parameters during the electro spinning process. Figures $3-5$ show the changes of the nano fiber diameter at different voltages, collection distances and rotation speeds. Figure 3 shows the changes of the nano fiber diameter with the increase of voltage at a constant distance of $180 \mathrm{~mm}$ and rotation speed of $10 \mathrm{rpm}$. The average fiber diameter of nano fibers decreased initially, and then did not decrease until the voltage was greater than $80 \mathrm{kV}$. This was due to the spinning solution not being able to be fully 
stretched under the lower electrostatic field force. However, when the voltage increased to $83 \mathrm{kV}$, more solution was available to be stretched from the spiral disk. Thus, the fiber diameter increased sharply.

Figure 4 shows the changes of the nano fiber diameter under different collection distances at a rotation speed of $15 \mathrm{rpm}$ and voltage of $74 \mathrm{kV}$. The average fiber diameter was minimum when the collection distance was $150 \mathrm{~mm}$, and the fiber diameter reached a maximum when the distance was $200 \mathrm{~mm}$. The decrease in the collection distance led to an increase in the electrostatic field force on the jets, which caused sufficient stretching. Figure 5 shows the changes of the nano fiber diameter under different rotation speeds at a constant distance of $180 \mathrm{~mm}$ and a voltage of $74 \mathrm{kV}$. With the increase of spiral disk rotation speed, the fiber diameter increased from $62 \mathrm{~nm}$ to $80 \mathrm{~nm}$, since more solution was ejected from the spiral disk.

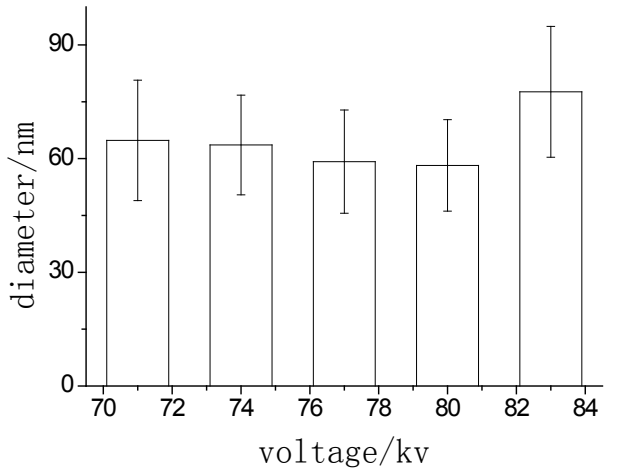

Figure 3 Changes of PVA/CS nano fiber diameters with different voltages.

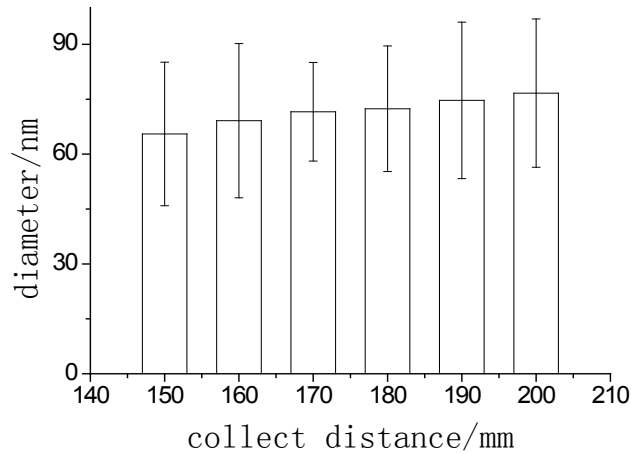

Figure 4 Changes of PVA/CS nano fiber diameters with different collection distances.

After the single factor analysis of electro spinning voltage, collection distance and rotation speed, we used an orthogonal experiment method of three factors and three levels Table 2 to analyze the optimal electro spinning parameters. The results of a three-factor and three-level orthogonal experiment are shown in Table 3. According to range analysis, electro spinning under a voltage of $78 \mathrm{kV}$, a rotation speed of $11 \mathrm{rpm}$, and a collection distance of $190 \mathrm{~mm}$ resulted in the most fine and uniform fibers with a diameter of $59.85 \mathrm{~nm}$ and $\mathrm{CV}$ of $17.75 \%$ Figure 6 . As the voltage was the least impacting factor, the rated voltage of the setup was set to $80 \mathrm{kV}$. If the voltage was set too high, it would easily cause the discharge phenomenon because of high humidity. Furthermore, when reducing the voltage to $75 \mathrm{kV}$ while keeping the other parameters constant, the fiber diameter was $60.95 \mathrm{~nm}$ and $\mathrm{CV}$ was $22.41 \%$. There was no significant intergroup difference with $78 \mathrm{kV}$. Considering all of the above factors, the optimal electro spinning process parameters were voltage of $75 \mathrm{kV}$, rotation speed of $11 \mathrm{rpm}$ and distance of $190 \mathrm{~mm}$.

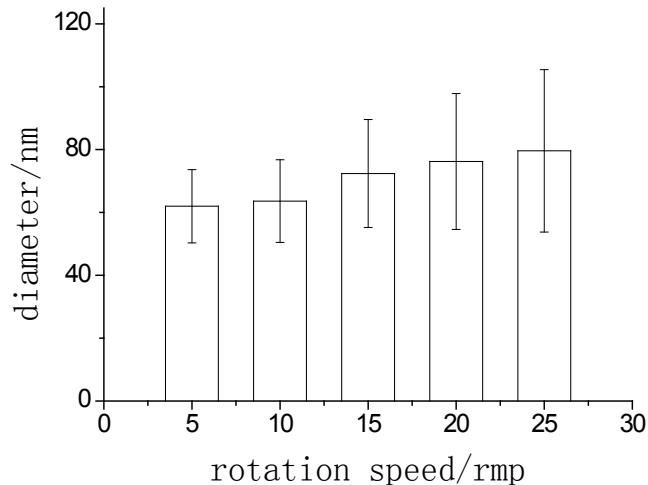

Figure 5 Changes of PVA/CS nano fiber diameters with different rotation speeds.

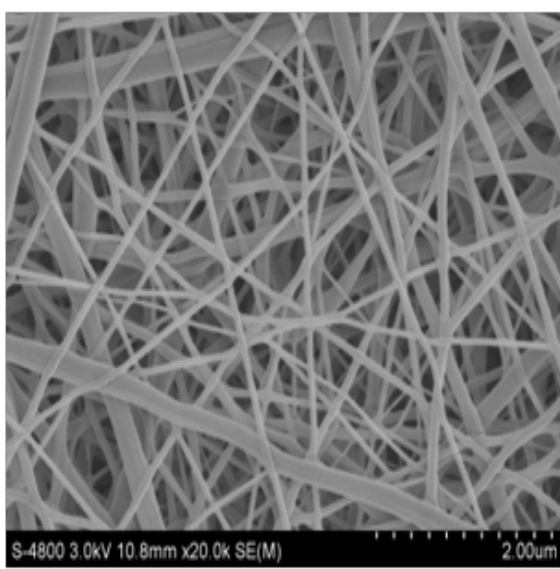

Figure 6 SEM image of PVA/CS nano fiber membrane generated at a voltage of $78 \mathrm{kV}$, rotation speed of I Irpm, and collection distance of $190 \mathrm{~mm}$.

Table 2 Orthogonal table of three factors and three levels

\begin{tabular}{llll}
\hline S.no & $\begin{array}{l}\text { A(voltage/ } \\
\mathbf{k V})\end{array}$ & $\begin{array}{l}\mathbf{B}(\text { flow rate/ } \\
\mathbf{m l} / \mathbf{h})\end{array}$ & $\begin{array}{l}\mathbf{C}(\text { Collection distancel } \\
\mathbf{c m})\end{array}$ \\
\hline $\mathrm{I}$ & 72 & 7 & 170 \\
2 & 75 & $1 \mathrm{I}$ & 180 \\
3 & 78 & 15 & 190
\end{tabular}

\section{Anti-water-soluble processing}

Heat treatment of PVA/CS nano fiber membranes: To improve the water resistance of the prepared PVA/CS nano fiber membranes, heat treatment was used due to it can help increasing the degree of crystallinity of PVA/CS molecular. ${ }^{29}$ What's more, it is a simple and environmental friendly way. By heat treatment, the will rise, to increase Differential scanning calorimetry analysis was used to investigate the melting points of PVA and CS. From Figure 7, the melting points of PVA and CS were found to be $190^{\circ} \mathrm{C}$ and $279.9^{\circ} \mathrm{C}$. Excessive heating above $190^{\circ} \mathrm{C}$ resulted in the destruction of the PVA quality. However, cross-linking could not be achieved ${ }^{27}$ if the temperature is too low. Thus, the heat temperature was set at $180^{\circ} \mathrm{C}$ Figure 8 shows the immersion of PVA/CS nano fiber membranes for $1 \mathrm{~h}$ after heating treatment for different times. After heat treating the 
nano fiber membranes for $3 \mathrm{~h}$ and $4 \mathrm{~h}$, the membranes were immersed in water $\left(25^{\circ} \mathrm{C}\right)$. The fibers swelled to a large degree shown in Figure $8 \mathrm{a} \& \mathrm{~b}$, and most of the interspace of nano fibers was blocked which hindered the air permeability and changed the morphology of the nano fibers immensely. However, heat treatment for $5 \mathrm{~h}$ did not alter the morphology of the fibers basically Figure 8(c). Considering the degree of fiber swelling and the fiber morphology, $180^{\circ} \mathrm{C}$ heat treatment for $5 \mathrm{~h}$ was the most preferable condition. It is worth noting that upon physical cross-linking by heating, a change in the color of the nano fibers from white to yellow was observed.

Table 3 Results of three factors three levels orthogonal experiment

\begin{tabular}{llllll}
\hline Experiment & A(Voltage/kV) & B(rotation speed /rpm) & C(distance/mm) & Diameter(nm) & CV(\%) \\
\hline I & I & I & 1 & 86.09 & 38.44 \\
2 & I & 2 & 2 & 96.19 & 22.89 \\
3 & $\mathrm{I}$ & 3 & 3 & 90.64 & 22.76 \\
4 & 2 & $\mathrm{I}$ & 2 & 72.69 & 24.03 \\
5 & 2 & 2 & 3 & 60.95 & 22.41 \\
6 & 2 & 3 & 1 & 110.39 & 24.16 \\
7 & 3 & 1 & 3 & 77.45 & 26.58 \\
8 & 3 & 2 & 1 & 70.4 & 29.53 \\
9 & 3 & 3 & 2 & 87.28 & 29.4 \\
k1 & 92.97 & 80.74 & 90.96 & & \\
k2 & 80.34 & 75.85 & 85.39 & & \\
k3 & 78.38 & 96.1 & 76.35 & & \\
R & 14.59 & 20.25 & 14.61 & & \\
\hline
\end{tabular}

GA vapor treatment: $\mathrm{GA}$ is a volatile liquid and can react with $-\mathrm{OH}$ in PVA, which can improve the water resistance of the nano fiber membranes. Vapor treatment is a mild way to decrease the damage to nano fibers during the process. Figure 9 shows the PVA/CS nano fiber membranes immersed in water for $1 \mathrm{~h}$ after exposure to GA vapor for different times. It can be observed that with an increase in GA exposure time, the degree of fiber swelling was reduced. However, the fiber membranes became yellow as shown in Figure 11(b) and brittle, which are not suitable for future applications.

GA solution treatment: GA could have acetal and hemiacetal reaction with PVA and CS to get higher water stability. PVA/CS nano fiber membranes were immersed into 5\% GA solution (acetone as the solvent) for $0.5 \mathrm{~h}$, followed by repeated washing using deionized water. Then, the membranes were placed into a vacuum drying oven at $40^{\circ} \mathrm{C}$ for $24 \mathrm{~h}$ to remove the GA residues. Figure 10 shows the GA solution treatment of PVA/CS nano fiber membranes. It can be seen that the membranes exhibited good anti-water-soluble properties. After immersion in water for $1 \mathrm{~h}$, no difference was observed in the fiber morphology, and the color of the membrane remained unchanged Figure 11(a). Figure 11 shows images of immersed PVA/CS nano fiber membranes in deionized water after different anti-water-soluble treatments. The original sizes were $4 \mathrm{~cm} \times 4 \mathrm{~cm}$. It can be clearly seen that the heat-treated membrane shrank considerably Figure 11 (c). The dimensional change rate was $25 \%$, which was the largest Table 4. Furthermore, the color of the membranes Figure $11 \mathrm{~b} \& \mathrm{c}$ turned yellow obviously. However, the membrane treated by GA solution Figure 11(a) retained its original shape and color; meanwhile, there was minimal, if any, weight loss. These results agreed with the fact that there was a great increase in the degree of water resistance when treated by GA solution.

Table 4 Weight loss and dimensional change rate of PVA/CS nano fiber membranes after different treatments

\begin{tabular}{|c|c|c|c|c|c|}
\hline $\begin{array}{l}\text { Sample } \\
\text { Treatment }\end{array}$ & $\begin{array}{l}\text { Before Immersing } \\
\text { in Water } W_{0 /} \mathrm{mg}\end{array}$ & $\begin{array}{l}\text { After Immersing in } \\
\text { Water } W_{1} / \mathbf{m g}\end{array}$ & $\begin{array}{l}\text { Weight Loss } \\
\text { Rate } W_{c} / \%\end{array}$ & $\begin{array}{l}\text { Size After } \\
\text { Immersing L/cm }\end{array}$ & $\begin{array}{l}\text { Dimensional } \\
\text { Change Rate } \\
\mathbf{L}_{c} / \%\end{array}$ \\
\hline $\begin{array}{l}\text { The original } \\
\text { sample }\end{array}$ & 12.6 & I.I & 91 & - & - \\
\hline GA vapor & 7.03 & 6.65 & 5 & $4 \times 4$ & 0 \\
\hline GA solution & 18.07 & $|8.0|$ & 3 & $4 \times 4$ & 0 \\
\hline Heat treatment & 2.95 & 2.9 & 2 & $3 \times 3$ & 25 \\
\hline
\end{tabular}




\section{Antibacterial activity}

The antibacterial properties of PVA/CS nano fiber membranes were studied using the oscillation method. Membranes with different CS concentrations from $1.0 \%$ to $1.5 \%$ were added into diluted bacteria solution oscillating at $24^{\circ} \mathrm{C}$ for $18 \mathrm{~h}$ and then poured onto plates with agar to culture at $37^{\circ} \mathrm{C}$ for $24 \mathrm{~h}$. E.coli and S. aureus were used as representative Gram-negative and Gram-positive microorganisms, respectively. Under the same conditions, PVA/CS efficiently inhibited the growth of E. coli and S. aureus, and the antibacterial resistance to E.coli was higher than that to S. aureus, as shown in (Table 5) (Table 6). Inhibition rates of all membranes to E.coli were above $99 \%$ and above $90 \%$ to S. aureus, thus indicating a high level of antibacterial activity. Considering that the test samples treated by GA solution may have bad effects to bacteria, control experiments were done using the heat treated membranes. As shown in Table 6, the inhibition rates were $90.5 \%$ and $91.4 \%$, respectively, thus showing no statistically significant differences. Thus, the GA solution treatment of PVA/CS fiber mat had no obvious influence on its antibacterial performance.

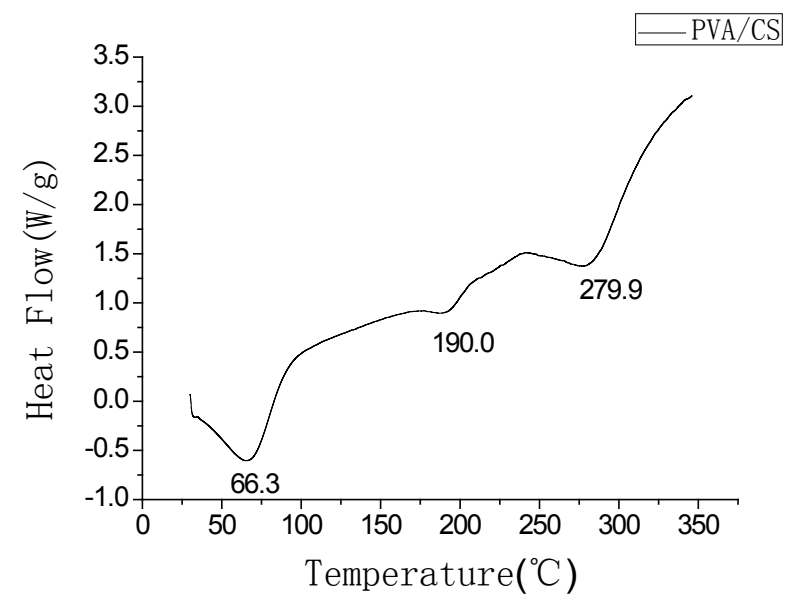

Figure 7 Differential scanning calorimetry analysis of PVA/CS nano fiber membrane.
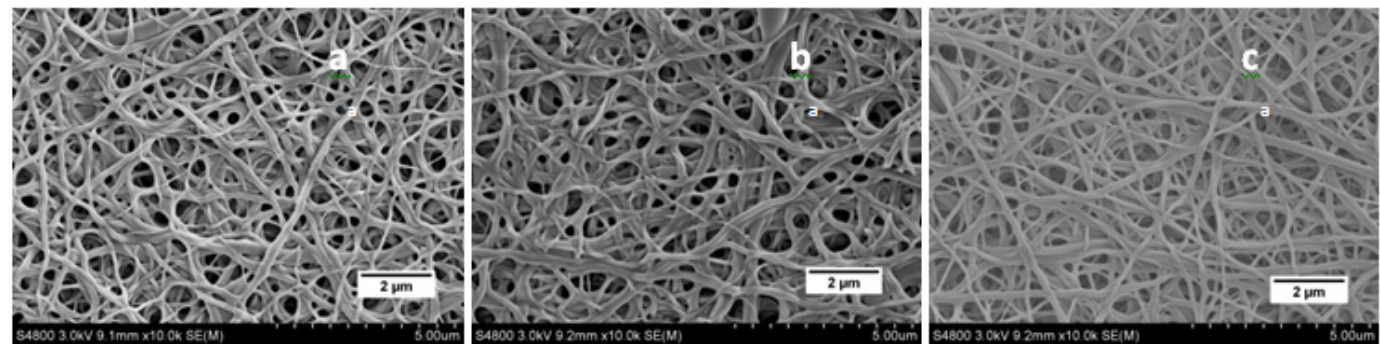

Figure 8 SEM images of immersed PVA/CS nano fiber membranes after heat treatmen̈t for different times: (a) heat treatment for $3 \mathrm{~h}$, (b) heat treatment for $4 \mathrm{~h}$ and (c) heat treatment for $5 \mathrm{~h}$.
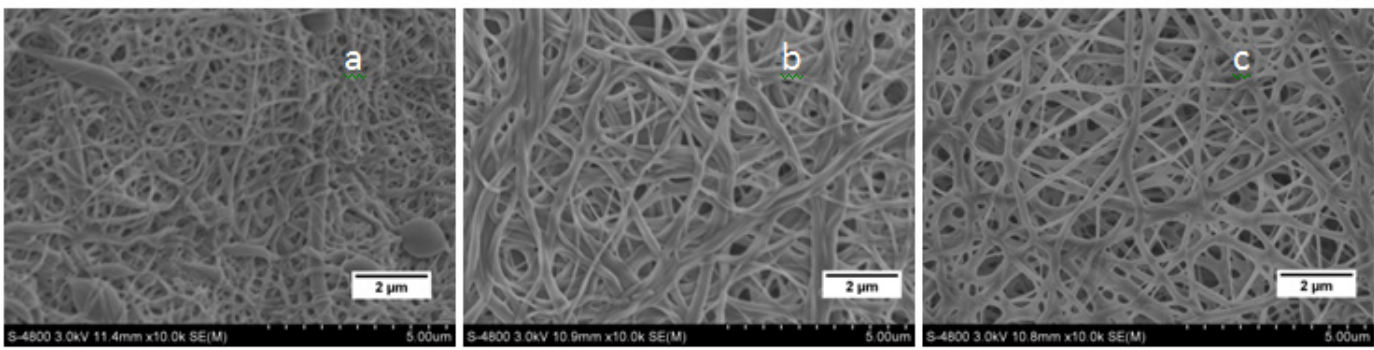

Figure 9 Pictures of immersed PVA/CS nano fiber membranes in water for I h after GA vapor treatment for (a) 36h, (b) 48h, and (c) 60h.

Table 5 Inhibition rates of PVA/CS nano fiber membranes to E. coli

\begin{tabular}{ll}
\hline Samples & Inhibition rate (\%) \\
\hline I.0\%+5\%PVA (GA solution treatment) & 99.9 \\
I.1\%+5\%PVA (GA solution treatment) & 99.6 \\
I. $\%+5 \%$ PVA (GA solution treatment) & 99.9 \\
$\begin{array}{l}\text { I.3\%+5\%PVA (GA solution treatment) } \\
\text { I.4\%+5\%PVA (GA solution treatment) }\end{array}$ & 99.9 \\
\hline & 99.9 \\
\hline
\end{tabular}

Table 6 Inhibition rates of PVA/CS nano fiber membranes to S. Aureus

\begin{tabular}{|c|c|}
\hline Samples & Inhibition rate (\%) \\
\hline $1.0 \%+5 \%$ PVA (GA solution treatment) & 97.3 \\
\hline I.I\%+5\%PVA (GA solution treatment) & 96.2 \\
\hline I.2\%+5\%PVA (GA solution treatment) & 94.6 \\
\hline I.3\%+5\%PVA (GA solution treatment) & 92.1 \\
\hline I.4\%+5\%PVA (GA solution treatment) & 99.3 \\
\hline I.5\%+5\%PVA (GA solution treatment) & 90.5 \\
\hline $1.5 \%+5 \%$ PVA (heat treatment) & 91.4 \\
\hline
\end{tabular}




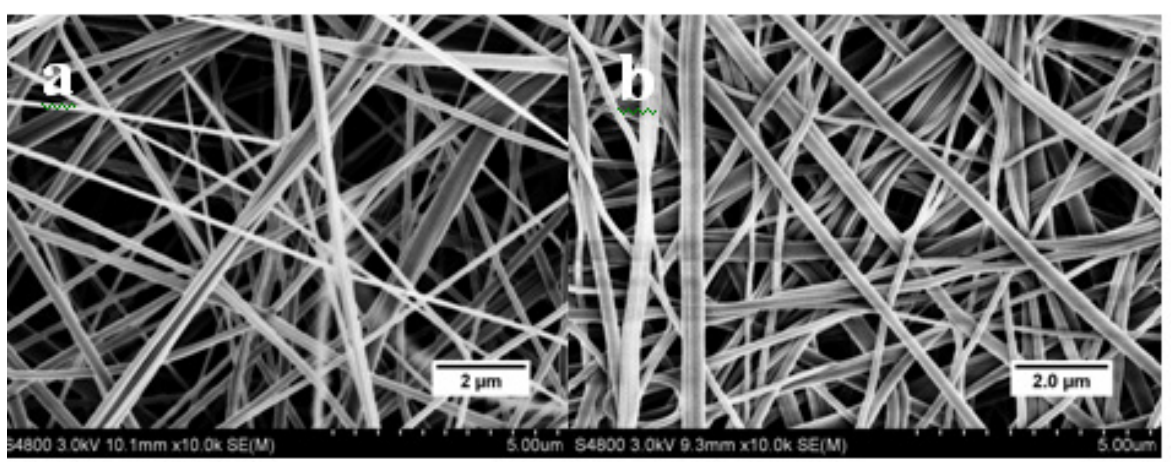

Figure 10 Pictures of PVA/CS nano fiber membranes after GA solution treatment: (a) before immersion in water and (b) after immersion in water for Ih.
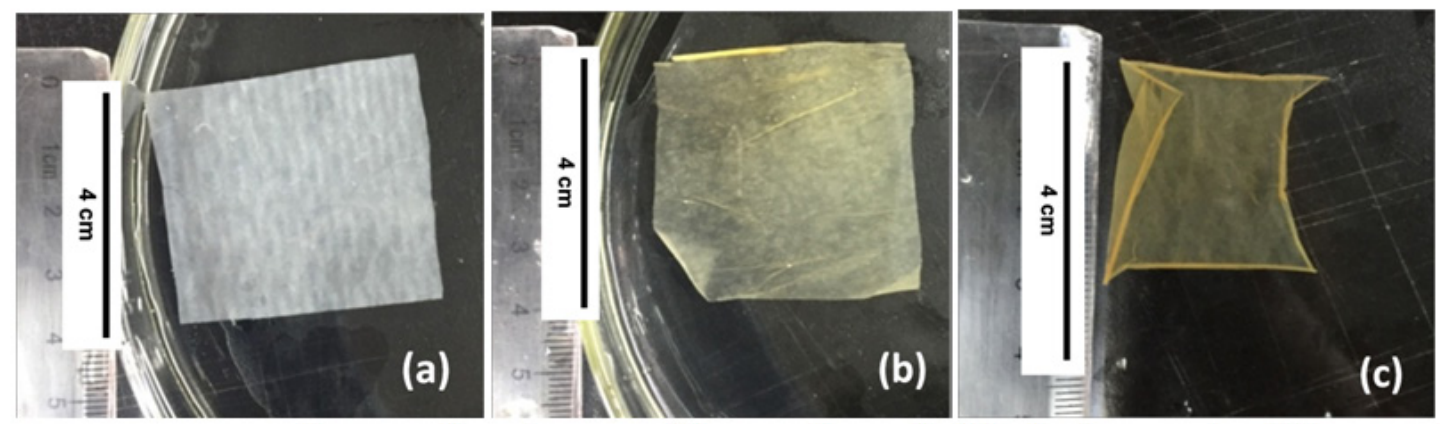

Figure II Images of immersed PVA/CS nano fiber membranes in deionized water after different anti-water-soluble treatments. (a) GA solution treatment, (b) GA vapors treatment, and (c) heat treatment at $180^{\circ} \mathrm{C}$ for $5 \mathrm{~h}$.

\section{Conclusion}

A needleless electro spinning device was used to fabricate PVA/ CS nano fiber membranes. The electro spinning voltage, collection distance and rotation speed were varied to obtain optimal electro spinning parameters, i.e., voltage of $75 \mathrm{kV}$, rotation speed of $11 \mathrm{rpm}$ and distance of $190 \mathrm{~mm}$. Three different methods were researched to increase the anti-water-soluble property. Based on the performances of the membranes and nano fibers, GA solution treatment is the better method, since its weight loss rate is $5 \%$ and nearly no size and color changes are observed after immersion in water. The antibacterial properties of PVA/CS nano fiber membranes with different CS concentrations were tested, and the results showed that the inhibition rates to E. coli are all above $99 \%$ and inhibition rates to S. aureus are above $90 \%$. From the control experiments, it was found that GA solution treatment has no obvious influence on the antibacterial activity. With superfine nano fibers and splendid antibacterial properties, the fabricated PVA/CS membranes could be used in air conditioning filters and other related fields.

\section{Acknowledgments}

None.

\section{Conflict of interest}

Author declares there is no conflict of interest in publishing the article.

\section{References}

1. Reneker DH, Yarin AL, Fong H, et al. Bending instability of electrically charged liquid jets of polymer solutions in electro spinning. Journal of Applied Physics. 2000;87(9):4531-4547.
2. Zhou FL, Gong RH, Porat I. Mass production of nano fiber assemblies by electrostatic spinning. Polymer International. 2009;58(4):331-342.

3. Aussawasathien D, Teerawattananon C, Vongachariya A. Separation of micron to sub-micron particles from water: Electrospun nylon-6 nano fibrous membranes as pre-filters. J Membrane Sci. 2008;315(1-2):11-19.

4. Barhate RS, Ramakrishna S. Nano fibrous filtering media: Filtration problems and solutions from tiny materials. J Membrane Sci.2007;296(1-2):1-9.

5. Greiner A, Wendorff JH. Electro spinning: a fascinating method for the preparation of ultrathin fibers. Angew Chem Int Ed Engl. 2007;46(30):5670-5703

6. Li D, Xia Y. Electro spinning of nano fibers: reinventing the wheel. Advanced Materials. 2004;16(14):1151-1170.

7. Tomaszewski W, Szadkowski M. Investigation of electro spinning with the use of a multi-jet electro spinning head. Fibres Text. East. Eur. 2005;4(52):22-26.

8. Yarin AL, Zussman E. Upward needleless electro spinning of multiple nano fibers. Polymer. 2004;45(9):2977-2980.

9. Thoppey NM, Bochinski JR, Clarke LI, et al. Unconfined fluid electrospun into high quality nano fibers from a plate edge. Polymer. 2010;51(21):4928-4936.

10. Thoppey NM, Bochinski JR, Clarke LI, et al. Edge electro spinning for high throughput production of quality nano fibers. Nanotechnology. 2011;22(34):345301.

11. Forward KM, Rutledge GC. Free surface electro spinning from a wire electrode. Chem Eng J. 2012;183:492-503.

12. Jiang G, Zhang S, Qin X. High throughput of quality nano fibers via one stepped pyramid-shaped spinneret. Mater Lett. 2013;106(1):56-58.

13. Zhou Z, Wu X, Ding Y, et al. Needleless emulsion electro spinning for scalable fabrication of core-shell nano fibers. $J$ Appl Polym. 2014;131(20):1-9. 
14. Holopainen J, Penttinen T, Santala E, et al. Needleless electro spinning with twisted wire spinneret. Nanotechnology. 2015;26(2):025301.

15. Wang X, Niu H, Lin T, et al. Needleless electro spinning of nano fibers with a conical wire coil. Polym Eng \& Sci. 2009;49(8):1582-1586.

16. Varabhas JS, Chase GG, Reneker DH. Electrospun nano fibers from a porous hollow tube. Polymer. 2008;49(19):4226-4229.

17.Zhou F, Gong R, Porat I. Three-jet electro spinning using a flat spinneret. J Mater Sci. 2009;44(20):5501-5508.

18. Kumar A, Wei M, Barry C, et al. Controlling Fiber Repulsion in Multijet Electro spinning for Higher Throughput. Macromol Mater Eng. 2010;295(8):701-708

19. Tang S, Zeng Y, Wang X. Splashing needleless electro spinning of nano fibers. Polym Eng Sci. 2010;50(11):2252-2257.

20. Lu B, Wang Y, Liu Y, et al. Super high-throughput needleless electro spinning using a rotary cone as spinneret. Small. 2010;6(15):1612-1616.

21. Dosunmu OO, Chase GG, Kataphinan W, et al. Electro spinning of polymer nano fibres from multiple jets on a porous tubular surface. Nanotechnology. 2006;17(4):1123-1127.

22. He JH, Liu Y, Xu L, et al. Biomimic fabrication of electrospun nano fibers with high-throughput. Chaos, Solitons \& Fractals. 2008;37(3):643-651.

23. Wang X, Niu H, Wang X, et al. Needleless electro spinning of uniform nano fibers using spiral coil spinnerets. Journal of Nanomaterials. 2012;2012(3):1-10.
24. Ignatova M, Starbova K, Markova N, et al. Electrospun nano-fibre mats with antibacterial properties from quaternised chitosan and poly(vinyl alcohol). Carbohydr Res. 2006;341(12):2098-2107.

25. Tonglairoum P. Thermally cross linked Chitosan-EDTA/PVA Electrospun Nano fiber Mats: Cross linking Conditions. Advan Mater Res. 2015;1060:192-195.

26. Sarhan WA, Azzazy HME. High concentration honey chitosan electrospun nano fibers: Biocompatibility and antibacterial effects. Carbohydrate Polymers. 2015;122:135-143.

27. Zhao C, Pan ZJ. Preparation and adhesion properties by needleless electro spinning of polyamide composite membranes using spiral piece spinnerets. J Text Res. 2015;36(11):27-33.

28. Cooper A, Oldinski R, Ma H, et al. Chitosan-based nanofibrous membranes for antibacterial filter applications. Carbohydr Polym. 2013;92(1):254-259.

29. Li S, Pan Z. Preparation of polyvinyl alcohol/chitosan composite nano fiber membrane by electro spinning. Modern Silk Science \& Technology. 2016;31(2):46-48. 